\title{
Magnesium chloride alone or in combination with diazepam fails to prevent hippocampal damage following transient forebrain ischemia
}

\author{
H. Milani ${ }^{1}$, \\ E.R. Lepri², \\ F. Giordani ${ }^{1}$ and \\ L.A. Favero-Filho ${ }^{1}$
}

\author{
Correspondence \\ H. Milani \\ Departamento de Farmácia e \\ Farmacologia, CCS \\ Universidade Estadual de Maringá \\ Av. Colombo, 5790 \\ 87020-900 Maringá, PR \\ Brasil \\ Fax: + 55-44-263-5116 \\ E-mail: milani@ dff.uem.br
}

Research supported by CNPq and UEM.

Received February 25, 1998 Accepted July 15, 1999

\author{
'Departamento de Farmácia e Farmacologia, Centro de Ciências da Saúde, and \\ ${ }^{2}$ Departamento de Ciências M orfofisiológicas, Centro de Ciências Biológicas, \\ Universidade Estadual de M aringá, M aringá, PR, Brasil
}

\section{Abstract}

In the central nervous system, magnesium ion $\left(\mathrm{Mg}^{2+}\right)$ acts as an endogenous modulator of N-methyl-D-aspartate (NMDA)-coupled calcium channels, and may play a major role in the pathomechanisms of ischemic brain damage. In the present study, we investigated the effects of magnesium chloride $\left(\mathrm{MgCl}_{2}, 2.5,5.0\right.$ or $\left.7.5 \mathrm{mmol} / \mathrm{kg}\right)$, either alone or in combination with diazepam (DZ), on ischemiainduced hippocampal cell death. Male Wistar rats (250-300 g) were subjected to transient forebrain ischemia for $15 \mathrm{~min}$ using the 4-vessel occlusion model. $\mathrm{MgCl}_{2}$ was applied systemically $(s c)$ in single $(1 \mathrm{x}, 2$ $\mathrm{h}$ post-ischemia) or multiple doses $(4 \mathrm{x}, 1,2,24$ and $48 \mathrm{~h}$ postischemia). DZ was always given twice, at 1 and $2 \mathrm{~h}$ post-ischemia. Thus, ischemia-subjected rats were assigned to one of the following treatments: vehicle $(0.1 \mathrm{ml} / \mathrm{kg}, \mathrm{N}=34), \mathrm{DZ}(10 \mathrm{mg} / \mathrm{kg}, \mathrm{N}=24), \mathrm{MgCl}_{2}$ (2.5 mmol $/ \mathrm{kg}, \mathrm{N}=10), \mathrm{MgCl}_{2}(5.0 \mathrm{mmol} / \mathrm{kg}, \mathrm{N}=17), \mathrm{MgCl}_{2}(7.5$ $\mathrm{mmol} / \mathrm{kg}, \mathrm{N}=9)$ or $\mathrm{MgCl}_{2}(5 \mathrm{mmol} / \mathrm{kg})+\mathrm{DZ}(10 \mathrm{mg} / \mathrm{kg}, \mathrm{N}=14)$. Seven days after ischemia the brains were analyzed histologically. Fifteen minutes of ischemia caused massive pyramidal cell loss in the subiculum (90.3\%) and CA1 (88.4\%) sectors of the hippocampus $(\mathrm{P}<0.0001$, vehicle $v s$ sham $)$. Compared to the vehicle-treated group, all pharmacological treatments failed to attenuate the ischemia-induced death of both subiculum (lesion: 86.7-93.4\%) and CA1 (lesion: 85.5-91.2\%) pyramidal cells $(\mathrm{P}>0.05)$. Both $\mathrm{DZ}$ alone and $\mathrm{DZ}+$ $\mathrm{MgCl}_{2}$ reduced rectal temperature significantly $(\mathrm{P}<0.05)$. No animal death was observed after drug treatment. These data indicate that exogenous magnesium, when administered systemically post-ischemia even in different multiple dose schedules, alone or with diazepam, is not useful against the histopathological effects of transient global cerebral ischemia in rats.

\section{Key words}

- Cerebral ischemia

- Hippocampal lesion

- CA1 cell loss

- Magnesium chloride

- Diazepam

- Neuroprotection 


\section{Introduction}

Transient global cerebral ischemia results in hippocampal cell death both in animal models $(1,2)$ and in humans, for example, victims of reversible cardiac arrest (3). Increased intracellular calcium seems to play an important role in the pathophysiology of delayed neuronal death caused by cerebral ischemia. Ischemia-induced calcium influx is coupled to the activation of voltagesensitive and agonist receptor-gated calcium channels, mainly the N-methyl-D-aspartate (NMDA) type of glutamate receptor $(4,5)$. Under resting conditions, the NMDAcoupled channel is normally blocked by $\mathrm{Mg}^{2+}$ $(6,7)$. However, during excessive depolarization, such as occurs during ischemia, this $\mathrm{Mg}^{2+}$ blockade is released (5). There is evidence of a relationship between the reduction or loss of the $\mathrm{Mg}^{2+}$ blockade of the NMDA response and persistent, neuronal hyperexcitability, which evolves to structural changes in the dendrites and finally to hippocampal cell death (8). Such neuronal overactivation may be related to the cause rather than the effect of ischemia-induced neurodegeneration since it can be detected long before cell loss (9). The role of endogenous $\mathrm{Mg}^{2+}$ in modulating calcium influx through the NMDA glutamate receptor makes it a candidate for neuroprotective therapy.

The neuroprotective potential of $\mathrm{Mg}^{2+}$ has been studied in different animal models of brain damage. Positive findings have been obtained in adult rodent models of in vitro anoxic challenge (10), in vivo glutamate neurotoxicity (11), spinal cord ischemia (12), focal ischemia following occlusion of the middle cerebral artery $(13,14)$ and, more extensively, in models of traumatic, mechanical brain injury (for a review, see Ref. 15). The effects of $\mathrm{Mg}^{2+}$ in attenuating delayed hippocampal cell death have been rarely investigated in in vivo animal models of transient global cerebral ischemia. Only a single study has attempted to evaluate the neuro- protective potential of $\mathrm{Mg}^{2+}$ after systemic delivery in adult rats subjected to transient forebrain ischemia. The intravenous injection of $\mathrm{MgCl}_{2}$ before ischemia not only failed to prevent CA1 hippocampal cell loss but aggravated the histological outcome (16). Clearly, further studies are necessary to provide more conclusive data on the effects of $\mathrm{Mg}^{2+}$ in animal models of transient global cerebral ischemia, including different treatment protocols.

The aim of the present study was to examine the effects of $\mathrm{MgCl}_{2}$ administered systemically using different schedules, either alone or in combination with diazepam (DZ), after ischemia. The 4-vessel occlusion (4-VO) model was used, thus extending findings to a more widely studied animal model of transient forebrain ischemia. The testing of the $\mathrm{MgCl}_{2}+\mathrm{DZ}$ combination is due to the fact that benzodiazepines potentiate the cell membrane hyperpolarization induced by activation of the GABA receptor/ion channel, thus inhibiting action potentials elicited by depolarization. Since ischemia-induced neuronal depolarization reduces the normal $\mathrm{Mg}^{2+}$ blockade of the NMDA-coupled calcium channel observed under resting conditions, we hypothesized that this effect of ischemia might be attenuated by the neuronal depressant action of DZ, thus facilitating the calcium blocking action of magnesium, independently of whether DZ alone may provide neuroprotection (17).

\section{Material and Methods}

\section{Subjects}

Male Wistar rats weighing 250-300 g at the beginning of the surgical procedures were used. The animals were maintained in groups of $4-5$ in plastic cages $(39 \times 33 \times 16 \mathrm{~cm})$ at a controlled temperature $\left(22 \pm 1{ }^{\circ} \mathrm{C}\right)$, on a 12 -h light/dark cycle (lights on at 7:00 a.m.). Food and water were offered ad libitum. Experimental procedures followed the "Basic Prin- 
ciples for Research Animal Utilization" published by the Brazilian Society for Neuroscience and Behavior.

\section{Ischemia}

Transient forebrain ischemia was induced using the 4-VO method (18) with the minor modifications described in a previous study (19). Under ether anesthesia plus the local application of $2 \%$ xylocaine, the vertebral arteries were electrocoagulated bilaterally and the carotid arteries were loosely snared with a silk thread. Five to six hours later, the thread was tightened for a period of $15 \mathrm{~min}$. Loss of the righting reflex within 2 min of carotid occlusion, unresponsiveness to a gentle touch, mydriasis and tonic extension of the paws were considered to indicate effective ischemia. Animals which recovered the righting reflex during the occlusion period or presented convulsions were excluded. After releasing the carotids, those animals which did not recover the red eye color within 2 min were also excluded. Core temperature, monitored by a rectal thermistor inserted to a depth of $6 \mathrm{~cm}$, was maintained between $37^{\circ}$ and $38^{\circ} \mathrm{C}$ throughout occlusion and during the first hours of reperfusion by placing the rats in a warming box at $30^{\circ} \mathrm{C}$ when necessary. Control rats were submitted to the same manipulations without occlusion of the vertebral and carotid arteries.

\section{Drug treatment}

$\mathrm{MgCl}_{2}(2.5,5.0$ or $7.5 \mathrm{mmol} / \mathrm{kg}, \mathrm{sc})$ was given either as a single dose $(1 \mathrm{x})$ or in multiple doses $(4 \mathrm{x})$. Diazepam $(10 \mathrm{mg} / \mathrm{kg}$, ip $)$ was always given twice, 1 and $2 \mathrm{~h}$ after initiating reperfusion (17). According to the treatment schedule the animals were assigned to one of the following groups: G1: shamoperated; G2: ischemia + vehicle (saline $0.9 \%, 0.2 \mathrm{ml} / 100$ g body weight, $s c, 4 \mathrm{x}) ; \mathrm{G} 3$ : ischemia $+\mathrm{DZ}(2 \mathrm{x}, 1$ and $2 \mathrm{~h}$ after reperfusion); G4: ischemia $+\mathrm{MgCl}_{2}(2.5 \mathrm{mmol} / \mathrm{kg}$;
$4 \mathrm{x} ; 1,2,24$ and $48 \mathrm{~h}$ after reperfusion); G5: ischemia $+\mathrm{MgCl}_{2}(5.0 \mathrm{mmol} / \mathrm{kg} ; 1 \mathrm{x}, 2 \mathrm{~h}$ after reperfusion); G6: ischemia $+\mathrm{MgCl}_{2}$ $(5.0 \mathrm{mmol} / \mathrm{kg}, 4 \mathrm{x}, 1,2,24$ and $48 \mathrm{~h}$ after reperfusion); $\mathrm{G} 7$ : ischemia $+\mathrm{MgCl}_{2}$ (7.5 $\mathrm{mmol} / \mathrm{kg} ; 4 \mathrm{x} ; 1,2,24$ and $48 \mathrm{~h}$ after reperfusion); G8: ischemia + DZ (2x; 1 and $2 \mathrm{~h}$ after reperfusion $)+\mathrm{MgCl}_{2}(5.0 \mathrm{mmol} / \mathrm{kg} ; 1 \mathrm{x} ; 2 \mathrm{~h}$ after reperfusion), and $\mathrm{G} 9$ : ischemia $+\mathrm{DZ}$ (2x; 1 and $2 \mathrm{~h}$ after reperfusion) $+\mathrm{MgCl}_{2}$ $(5.0 \mathrm{mmol} / \mathrm{kg}, 4 \mathrm{x}, 1,2,24$, and $48 \mathrm{~h}$ after reperfusion).

$\mathrm{MgCl}_{2} .7 \mathrm{H}_{2} \mathrm{O}$ was purchased from Sigma Chemical Co., St. Louis, MO, USA; Diazepam ${ }^{\circledR}$ was a commercial preparation from Roche Pharmaceutic Inc., São Paulo, Brazil.

\section{Histological analysis}

On the 7th day after ischemia, the animals were anesthetized deeply with ether and perfused transcardiacally with $0.9 \%$ saline followed by Bouin's fixative solution at a rate of $20 \mathrm{ml} / \mathrm{min}$ for 7-10 min. The brain was kept in situ for $1 \mathrm{~h}$ at $1-2^{\circ} \mathrm{C}$ and then removed and kept in the same fixative for 3 days. Eight to twelve coronal sections were taken from each brain at levels corresponding to $3.0-4.0 \mathrm{~mm}$ posterior to bregma, and stained with hematoxylin-eosin. Three sections were chosen for each bilateral count. Thus, 6 fields were counted per rat and the number of apparently intact cells per animal was reported as the mean of the 6 fields. Fields were chosen by centering the $400 \mathrm{X}$ microscopic field on the medial portion of the subiculum and CA1 sectors. The identity of treatment groups was unknown to the examiner during the histological analysis.

\section{D ata analysis}

One-way ANOVA was used to evaluate the effects of the pharmacological treatments on the number of intact-appearing pyramidal cells in the subiculum and CA 1 sectors of the hippocampus. When a significant main ef- 
fect appeared, Duncan's multiple range test was performed to determine differences between groups. The effect of the pharmacological treatments on rectal temperature was analyzed by MANOVA with repeated measures followed by the Newman-Keuls test. In the case of a significant group effect, the Student $t$-test was used to compare the respective groups for a given interval.

\section{Results}

Compared to the sham-operated group,

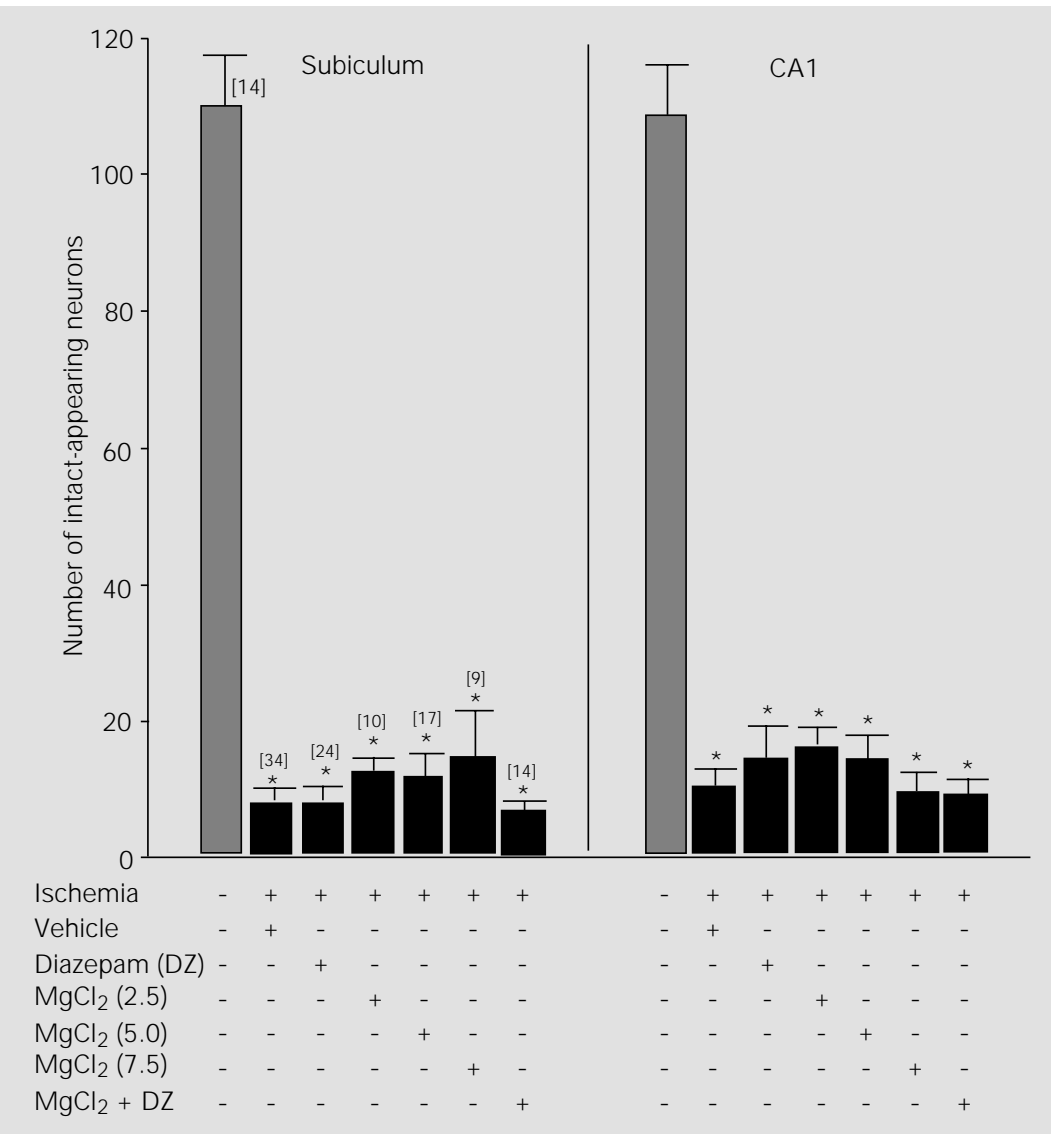

Figure 1 - Effect of $\mathrm{MgCl}_{2}(2.5,5.0$ or $7.5 \mathrm{mmol} / \mathrm{kg}, \mathrm{sc})$ either alone or in combination with diazepam (DZ) $\left(\mathrm{MgCl}_{2}+\mathrm{DZ}, 5 \mathrm{mmol} / \mathrm{kg}\right.$ and $10 \mathrm{mg} / \mathrm{kg}$, ip, respectively) on hippocampal pyramidal cell loss after 15-min transient forebrain ischemia. The effect of $5.0 \mathrm{mmol} / \mathrm{kg}$ $\mathrm{MgCl}_{2}$ was tested after a single dose ( $1 \mathrm{x}, 2 \mathrm{~h}$ post-ischemia) or multiple $(4 \mathrm{x}, 1,2,24$ and 48 $\mathrm{h}$ post-ischemia) doses. The 2.5 and $7.5 \mathrm{mmol} / \mathrm{kg} \mathrm{MgCl}_{2}$ doses were tested after multiple administration ( $4 \mathrm{x})$ only. The animals treated with a single dose $(1 \mathrm{x})$ or multiple $(4 \mathrm{x})$ doses of $\mathrm{MgCl}_{2}(5.0 \mathrm{mmol} / \mathrm{kg})$ were pooled, as were the groups treated with $\mathrm{MgCl}_{2}(1 \mathrm{x})+\mathrm{DZ}$ or $\mathrm{MgCl}_{2}(4 \mathrm{x})+\mathrm{DZ}$. Diazepam (10 mg/kg), alone or in combination with $\mathrm{MgCl}_{2}$, was always given twice ( 1 and $2 \mathrm{~h}$ after reperfusion). Bars and vertical lines represent the mean and SEM. The numbers within brackets indicate the sample size. ${ }^{*} \mathrm{P}<0.0001$ vs the shamoperated group.
15 min of ischemia caused a profound loss of pyramidal neurons in the subiculum $\left(\mathrm{F}_{6,113}=\right.$ 100.7; $\mathrm{P}<0.0001)$ and $\mathrm{CA} 1\left(\mathrm{~F}_{6,113}=65.9\right.$; $\mathrm{P}<0.0001$ ) sectors of the hippocampus in all groups (Figure 1). The degree of cell loss ranged from 86.7 to $94.0 \%$ in the subiculum and from 85.3 to $91.6 \%$ in the CA1 sectors. When given in different amounts and in single or multiple doses $\mathrm{MgCl}_{2}$ did not provide a neuroprotective effect against ischemia-induced pyramidal cell loss in the subiculum and CA1 hippocampal sectors compared to the vehicle-treated group (Figure 1) ( $\mathrm{P}>0.05$, Duncan's multiple range test). The treatment with diazepam alone, given 1 and $2 \mathrm{~h}$ after reperfusion, also did not exert a neuroprotective effect. These results for the single drug protocol did not change with the $\mathrm{MgCl}_{2}$ plus diazepam combination. No difference was observed among the various pharmacological treatments.

$\mathrm{MgCl}_{2}$ caused a consistent and apparently dose-dependent loss in muscle tonus, indicating that the substance was well absorbed. However, no rat died or required artificial respiration. Profound sedation was observed in rats given $\mathrm{DZ}$ alone or $\mathrm{MgCl}_{2}+$ DZ. Compared to the vehicle-treated group, there was a slight but significant reduction in core temperature after treatment with either $\mathrm{DZ}$ alone or $\mathrm{MgCl}_{2}+\mathrm{DZ}(\mathrm{P}<0.05)$ (Figure 2). This effect may have been due to the action of DZ since there was no difference between the vehicle- and $\mathrm{MgCl}_{2}$ treated groups or the $\mathrm{DZ}$ and $\mathrm{MgCl}_{2}+\mathrm{DZ}$ groups.

\section{Discussion}

The present study demonstrates that the systemic application of increasing doses of $\mathrm{MgCl}_{2}$ employing either a single or multiple administration schedule does not provide neuroprotection against delayed hippocampal cell death induced by transient forebrain ischemia in the adult rat. This situation is unaltered when DZ is added to $\mathrm{MgCl}_{2}$, even 
though a modest fall in rectal temperature was recorded.

The lack of a neuroprotective effect of hypothermia is consistent with findings showing that hypothermia may prevent cell death when occurring during the intra-ischemic or immediate (5 $\mathrm{min}$ ) post-ischemic periods, but not after longer (30 $\mathrm{min})$ post-ischemic periods (for a review, see Refs. 17,20). In the present study, hypothermia appeared only in the groups treated with $\mathrm{DZ}$ or $\mathrm{DZ}+\mathrm{MgCl}_{2}$ 60 min following reperfusion (Figure 2).

Our data for magnesium are consistent with a previous study which not only failed to demonstrate a neuroprotective effect of $\mathrm{MgCl}_{2}$, but detected worsening of ischemiainduced hippocampal cell loss (16). This effect of $\mathrm{MgCl}_{2}$ was not observed in the present experiments. A possible explanation may be the difference in the methodology used to produce transient cerebral ischemia in the two studies. In Blair's experiments, animals were subjected to $10 \mathrm{~min}$ ischemia by a combination of intravenous trimethaphan, bilateral carotid artery occlusion and simultaneous central venous exsanguination, which required that the animal be maintained under anesthesia. Thus, the onset and maintenance of ischemia was judged on the basis of an isoelectric electroencephalogram (EEG). As noted by others, this parameter is not an adequate index of the severity of ischemia since isoelectricity of the EEG may occur in the presence of electrophysiological activity, and therefore considerable blood flow, in the hippocampus (21). In the present study, we used the 4-VO model in which animals are not anesthetized during or after ischemia. Thus, clinical criteria such as loss of the righting reflex, mydriasis, lack of responsiveness to touch, and tonic extension of the paws were used; these acute symptoms are indicative of severe forebrain ischemia (21). Unlike the present model, in that used by Blair et al. (16) mild ischemia may have been produced leading to submaximal hippocampal cell loss; this may account for the aggravating effect of $\mathrm{MgCl}_{2}$. In the present study, however, the almost complete loss of pyramidal cells may have masked the aggravating effect of $\mathrm{MgCl}_{2}$, had it occurred.

Hyperglycemia induced by $\mathrm{MgCl}_{2}$ may be the cause of the aggravating effect of this compound on the histological outcome of ischemia (16). It is well established that preischemic hyperglycemia worsens the outcome of transient ischemia. Although plasma glucose was not measured after the administration of $\mathrm{MgCl}_{2}$ in the present experiment, it is unlikely that hyperglycemia may have masked the neuroprotective properties of magnesium. In fact, Blair et al. (16) have found that while insulin prevents worsening of the histological changes caused by $\mathrm{MgCl}_{2}$, it does not change the extent of hippocampal cell loss caused by ischemia in comparison to the control group. This suggests that the failure of $\mathrm{MgCl}_{2}$ to counteract the histological changes resulting from ischemia was not due to the masking effect of hyperglycemia. In a model of focal ischemia, however, insu-

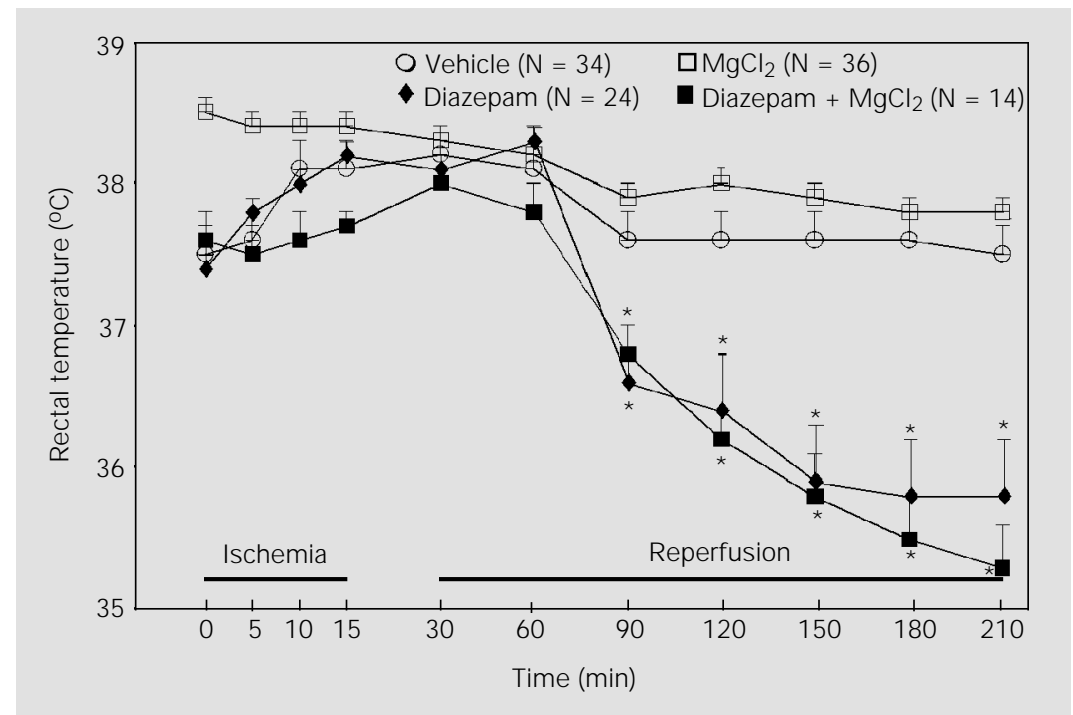

Figure 2 - Effect of $\mathrm{MgCl}_{2}$ and diazepam alone or in combination on rectal temperature. The groups assigned to the $\mathrm{MgCl}_{2}(2.5,5.0$ or $7.5 \mathrm{mmol} / \mathrm{kg}$ ) treatments, either as a single dose or as multiple doses, were pooled since core temperatures did not differ among the individual groups. The groups treated with both substances were also pooled, i.e., $\mathrm{MgCl}_{2}$ $(1 \mathrm{x})+\mathrm{DZ}$ and $\mathrm{MgCl}_{2}(4 \mathrm{x})+\mathrm{DZ}$. $* \mathrm{P}<0.05$ vs vehicle group. Data are reported as the mean \pm SEM. 
lin treatment potentiated the effect of $\mathrm{MgCl}_{2}$ in reducing infarct size (14). Additionally, in the present study, $\mathrm{MgCl}_{2}$ was administered 1 $\mathrm{h}$ post-ischemia, an interval during which adequate circulation would be restored avoiding exacerbated anaerobic metabolism of glucose with elevated lactate formation. Thus, in the present study, the lack of a neuroprotective effect after the systemic administration of $\mathrm{MgCl}_{2}$ cannot be explained by the detrimental influence of possible $\mathrm{MgCl}_{2}$-induced hyperglycemia.

In the study of Blair et al. (16), $\mathrm{MgCl}_{2}$ was given in a single dose prior to ischemia. These authors suggested that the failure of such treatment to protect against ischemia might have resulted from the "lack of a maintained elevation of $\mathrm{Mg}^{2+}$ concentration in the extracellular fluid beyond the acute insult, and that $\mathrm{Mg}^{2+}$ would be more beneficial if provided 2-3 days after ischemia". In this respect, our data extend these findings, demonstrating that even with different and repeated doses given 1, 2, 24 and $48 \mathrm{~h}$ after reperfusion, $\mathrm{MgCl}_{2}$ failed to prevent hippocampal cell loss after transient, global forebrain ischemia. Whether this protocol provided a consistent $\mathrm{Mg}^{2+}$ concentration in brain parenchyma is not known. However, data from the literature indicate that although $\mathrm{Mg}^{2+}$ can cross the blood brain barrier (BBB), this occurrence may be greatly restricted. For example, in dogs, $\mathrm{Mg}^{2+}$ concentration increased to a maximum of $21 \%$ in the cerebrospinal fluid (CSF) compared to the 300$400 \%$ elevation in plasma after intravenous administration of $\mathrm{MgCl}_{2}$ (22). Under conditions of hypomagnesemia, the mean $\mathrm{Mg}^{2+}$ concentration in the whole brain was negligible one hour after a single intraperitoneal injection of $\mathrm{MgCl}_{2}$; an increase in $\mathrm{Mg}^{2+}$ concentration in the CSF does not reflect an increase in the brain parenchyma (23). In normal rats, the administration of $432 \mathrm{mg} / \mathrm{kg}$ of $\mathrm{MgSO}_{4}$ given in several doses over a 2-h period elevated the level of $\mathrm{Mg}^{2+}$ in the hippocampus by $41 \%(24)$. In another study,
20 min of 4-vessel occlusion elevated the $\mathrm{Mg}^{2+}$ concentration in the hippocampus by $28 \%$ after $24 \mathrm{~h}$ of reperfusion, which decreased progressively to 19 and $15.6 \%$ above the control after 48 and $72 \mathrm{~h}$ of reperfusion, respectively. This rise in intrahippocampal $\mathrm{Mg}^{2+}$ levels from an internal source did not confer a neuroprotective effect after ischemia (25). However, the extent to which systemically applied exogenous magnesium can enter the brain after transient, global ischemia has not been investigated.

In the present experiments, the animals received different doses of $\mathrm{MgCl}_{2}$, i.e., 2.5, 5.0 and $7.5 \mathrm{mmol} / \mathrm{kg}$, during the first and second hours after reperfusion, for a total of 476,952 and $1,428 \mathrm{mg} / \mathrm{kg}$, respectively, over a 2 -h period. The last dose corresponds to more than three times the amount of $\mathrm{MgCl}_{2}$ used in the study cited above (24). Considering that transient global ischemia results in increased permeability of the BBB to small and large molecules $(26,27)$ possibly including $\mathrm{Mg}^{2+}(28)$, it would be expected in the present experiment with ischemic rats that the $\mathrm{Mg}^{2+}$ concentration in the hippocampus might be similar to or even greater than that found in normal rats (24), at least during the first two hours of reperfusion (see 28). If so, the exogenous $\mathrm{Mg}^{2+}$ concentration which reached the brain parenchyma in the present study may have been insufficient to provide hippocampal neuroprotection. This may be true, since the local application of a single injection of $\mathrm{MgCl}_{2}(50 \mathrm{mM} / 1 \mu \mathrm{l})$ into the hippocampus reduces hippocampal cell loss after $20 \mathrm{~min}$ of ischemia in the 4-VO model (25). This finding corroborates other data obtained using in vitro models of ischemia (10), indicating that the lack of an $\mathrm{Mg}^{2+}$ neuroprotective effect after systemic administration may not result from pharmacodynamic ineffectiveness. That the BBB may limit the bioavailability of exogenously applied $\mathrm{Mg}^{2+}$, even during transient forebrain ischemia, is supported by other observations. 
There is evidence that disruption of the BBB by transient global cerebral ischemia may occur in a mild to moderate manner. In the 4-VO rat model, the permeability of the BBB to small and large molecules was altered only in the presence of tissue infarction (29). Infarction, however, is infrequent in this model of cerebral ischemia even after 30 min or more (1,29). Pluta et al. (30) reported that after 10 min of cardiac arrest in the rat, horseradish peroxidase (HRP) extravasations, although constant, were few, randomly distributed and focal, and appeared most frequently in certain brain regions including the hippocampus. Overall, infarction appeared occasionally as single or multiple microscopic foci. These changes were not graded as a function of the duration of ischemia and/or reperfusion. Pluta et al. (30) concluded that such alterations may "reflect more a slight and random leakage associated with only a limited number of vessel bifurcations, rather than a massive BBB breakdown". In contrast, in models of focal ischemia, infarction invariably occurs in the region supplied by the occluded vascular tree. Its magnitude is dependent on the duration of ischemia, and the BBB breakdown is dramatic (31$34)$. In cats, the BBB permeability to pertechnetate, albumin, sodium and antipyrine was greatest in the core and lowest in the penumbral region of the infarct after middle cerebral artery occlusion (34). The extent of BBB disruption seems to be a phenomenon dependent on the nature and severity of brain injury (33) which should determine the bioavailability of drugs at the site of damage. This may partially explain why $\mathrm{Mg}^{2+}$ treatment applied systemically is effective in preventing brain damage in animal models of focal ischemia $(14,15)$, spinal cord ischemia (13), traumatic brain injury (10), and neurotoxic injury induced by local application of quinolinate (35), but not in models of transient forebrain global ischemia (16, present results).

Thus, the lack of a neuroprotective effect by $\mathrm{MgCl}_{2}$ in the present study (see also Ref. 16) may be partially attributed to pharmacokinetic hindrance at the level of the BBB, limiting the bioavailability of $\mathrm{Mg}^{2+}$ to the brain parenchyma, even under transient global ischemia. In addition, other factors may act to reduce $\mathrm{Mg}^{2+}$ concentration in the brain after systemic administration, e.g., the short half-time of magnesium in the CSF, estimated to be about $75 \mathrm{~min}$ in the mongrel dog (22), and the finding that, at least in humans, about $33 \%$ of plasma magnesium is proteinbound (36) and unavailable to the brain.

The combination of $\mathrm{MgCl}_{2}+\mathrm{DZ}$ did not alter the results observed for each compound alone. The rationale for testing the drug combination lies in the well-established neuronal depressant action of DZ, i.e., an effect contrary to the cell membrane depolarization that occurs during ischemia $(8,9)$. Thus, independently of whether DZ does (17) or does not provide (present results) neuroprotection, our hypothesis holds that DZ may facilitate the expression of a neuroprotective effect by $\mathrm{Mg}^{2+}$ (see Introduction). The failure to observe a neuroprotective effect of DZ in the present study differs from the findings of Schwartz et al. (17). The reason for this discrepancy is not clear. However, while the animal model and the pharmacological treatment were the same in both studies, two important procedural differences should be noted. First, in Schwartz's study (17), the presence of cerebral ischemia was demonstrated by the occurrence of EEG isoelectricity, as in the study reported by Blair et al. (16) and discussed above. Thus, compared to our study, the ischemia in the study of Schwartz et al. (17) may not have been too severe. DZ may be effective under such conditions. The second difference concerns the post-ischemic survival period after which the animals were sacrificed for histological analysis: 4 days in Schwartz's study compared to 7 days in the present work. This variable may be important when considering the neuroprotective effects of drugs after 
certain types of brain injury since drugs may slow the rate of the neuronal death but not avoid it. Thus, the neuroprotective effect of DZ observed by Schwartz et al. (17) may not be long lasting; DZ may have merely delayed hippocampal cell death (17). In another study, Schwartz et al. (37) found that the GABA reuptake inhibitor tiagabine was neuroprotective up to 4 days post-ischemia, but not after 21 days. Under the present experimental conditions, however, one limitation of this study was that the negative result with $\mathrm{DZ}$ alone hinders an interpretation as to whether DZ does or does not facilitate the neuroprotective action of $\mathrm{Mg}^{2+}$. Under different experimental conditions, both DZ (17) and $\mathrm{Mg}^{2+}(10-15)$ are neuroprotective.

The data presented here suggest that $\mathrm{MgCl}_{2}$, when given systemically in single or multiple doses, is not useful to protect against acute neurodegenerative outcomes in models of transient global ischemia. Whether DZ interacts with $\mathrm{Mg}^{2+}$ to facilitate its pharmacodynamic effectiveness will require additional studies.

\section{Aknowledgments}

The authors gratefully acknowledge the technical assistance of Marcos A. Trombelli.

\section{References}

1. Pulsinelli WA, Brierley J B \& Fred P (1982). Temporal profile of neuronal damage in a model of transient forebrain ischemia. Annals of Neurology, 11: 491-498.

2. Kirino T, Tamura A \& Sano K (1984). Delayed neuronal death in the rat hippocampus following transient forebrain ischemia. Acta Neuropathologica, 64: 139-147.

3. Petito CK, Feldmann E, Pulsinelli WA \& Plum F (1987). Delayed hippocampal damage in humans following cardiorespiratory arrest. Neurology, 37: 1281-1286.

4. Raichle ME (1983). The pathophysiology of brain ischemia. Annals of Neurology, 13: 2-10

5. Siesjo BK \& Bengtsson F (1989). Calcium fluxes, calcium antagonists, and calciumrelated pathology in brain ischemia, hypoglycemia, and spreading depression: a unifying hypothesis. J ournal of Cerebral Blood Flow and Metabolism, 9: 127-140.

6. Novak L, Bregestovski P, Ascher P, Herbet A \& Prochiantz A (1984). Magnesium gates glutamate-activated channels in mouse central neurones. Nature, 307: 462-465.

7. Coan EJ \& Collingridge GL (1985). Magnesium ions block an $\mathrm{N}$-methyl-D-aspartate receptor-mediated component of synaptic transmission in rat hippocampus. Neuroscience Letters, 53: 21-26.

8. Hori N \& Carpenter DO (1994). Functional and morphological changes induced by transient in vivo ischemia. Experimental Neurology, 129: 279-289.

9. Gao TM \& Xu ZC (1996). In vivo intracellular demonstration of an ischemia-induced postsynaptic potential from CA1 pyramidal neurons in rat hippocampus. Neuroscience, 75: 665-669.

10. Kass IS, Cottrell J E \& Chambers G (1988). Magnesium and cobalt, not nimodipine, protect neurons against anoxic damage in the rat hippocampal slice. Anesthesiology, 69: 710-715.

11. Rothe F, Wolf G, Fische S, Hass P, Keilhoff G \& Abicht K (1993). Quinolinate and kainate facilitate magnesium penetration into brain tissue. Neuroreport, 4: 205207.

12. Vacanti FX \& Ames III A (1984). Mild hypothermia and $\mathrm{Mg}^{++}$protect against irreversible damage during CNS ischemia. Stroke, 15: 695-698.

13. Izumi Y, Roussel S, Pinard E \& Seylaz J (1991). Reduction of infarct volume by magnesium after middle cerebral artery occlusion in rats. J ournal of Cerebral Blood Flow and Metabolism, 11: 10251030.

14. Marinov MB, Harbaugh KS, Hoopes PJ , Pikus HJ \& Harbaugh RE (1996). Neuroprotective effects of preischemia intraarterial magnesium sulfate in reversible focal cerebral ischemia. J ournal of Neurosurgery, 85: 117-124.

15. Mclntoshi TK (1994). Neurochemical sequelae of traumatic brain injury: Therapeutic implications. Cerebrovascular and Brain Metabolism Reviews, 6: 109-162.

16. Blair J L, Warner DS \& Todd MM (1989). Effects of elevated plasma magnesium versus calcium on cerebral ischemic injury in rats. Stroke, 20: 507-512.
17. Schwartz RD, YuX, Katzman MR, HaydenHixson DM \& PerryJ M (1995). Diazepam, given postischemia, protects selectively vulnerable neurons in the rat hippocampus and striatum. Journal of Neuroscience, 15: 529-539.

18. Pulsinelli WA \& Brierley J B (1979). A new model of bilateral hemispheric ischemia in the unanesthetized rat. Stroke, 10: 267 272.

19. Milani $\mathrm{H}$, Uemura $\mathrm{YU}$, Oliveira RMW, Lepri ER \& Xavier GF (1998). Loss of CA1 cells following global ischaemia correlates with spatial deficits in the circular platform task. J ournal of Neuroscience Methods, 80: 19-27.

20. Dietrich WD (1992). The importance of brain temperature in cerebral injury. J ournal of Neurotrauma, 9: S475-S485.

21. Buchan A, Li H \& Pulsinelli WA (1991). The N-methyl-D-aspartate antagonist, M K801 , fails to protect against neuronal damage caused by transient, severe forebrain ischemia in adult rats. J ournal of Neuroscience, 11: 1049-1056.

22. Oppelt WW, MacIntyre I \& Rall DP (1963). Magnesium exchange between blood and cerebrospinal fluid. American J ournal of Physiology, 205: 959-962.

23. Chutkow J G (1974). Metabolism of magnesium in central nervous system: Relationship between concentrations of magnesium in cerebrospinal fluid and brain in magnesium deficiency. Neurology, 24: 780-787.

24. Hallak M, Berman RF, Irtenkauf SM, Evans MI \& Cotton DB (1992). Peripheral 
magnesium sulfate enters the brain and increases the threshold for hippocampal seizures in rats. American J ournal of Obstetrics and Gynecology, 167: 1605-1610.

25. Tsuda T, Kogure K, Nishioka $K \&$ Watanabe T (1991). $\mathrm{Mg}^{2+}$ administered up to twenty-four hours following reperfusion prevents ischemic damage of the CA1 neurons in the rat hippocampus. Neuroscience, 44: 335-341.

26. Dobbin J , Crockard HA \& Ross-Russel R (1989). Transient blood-brain barrier permeability following profound temporary global ischemia: an experimental study using $\left[{ }^{14} \mathrm{C}\right]$ AlB. J ournal of Cerebral Blood Flow and Metabolism, 9: 71-78.

27. Preston E \& Foster DO (1997). Evidence for pore-like opening of the blood-brain barrier following forebrain ischemia in rats. Brain Research, 761: 4-10.

28. Ito U, Ohno K, Nakamura R, Suganuma F \& Inaba Y (1979). Edema during ischaemia and after restoration of blood flow. Measurement of water, sodium, potassium content and plasma protein permeability. Stroke, 10: 542-547.
29. Petito CK, Pulsinelli WA, J acobson $G \&$ Plum F (1982). Edema and vascular permeability in cerebral ischemia: comparison between ischemic neuronal damage and infarction. J ournal of Neuropathology and Experimental Neurology, 41: 423-436.

30. Pluta R, Lossinsky AS, Wisniewski HM \& Mossakowski MJ (1994). Early blood-brain barrier changes in the rat following transient complete cerebral ischemia induced by cardiac arrest. Brain Research, 633: 41-52.

31. Hatashita S \& Hoff J T (1990). Brain edema and cerebrovascular permeability during cerebral ischemia in rats. Stroke, 21: 582588.

32. Garcia J H, Yoshida Y, Chen H, Li Y, Zhang ZG, Lian J, Chen S \& Chopp M (1993). Progression from ischemic injury to infarct following middle cerebral artery occlusion in the rat. American J ournal of Pathology, 142: 623-635.

33. Belayev L, Busto R, Zhao W \& Ginsberg MD (1996). Quantitative evaluation of blood-brain barrier permeability following middle cerebral artery occlusion in rats.
Brain Research, 739: 88-96.

34. O'Brien MD, J ordan MM \& Waltz AG (1974). Ischemic cerebral edema and the blood-brain barrier: Distributions of pertechnetate, albumin, sodium, and antipyrine in brains of cats after occlusion of the middle cerebral artery. Archives of Neurology, 30: 461-465.

35. Wolf $G$, Keilhoff $G$, Fischer $S \&$ Hass $P$ (1990). Subcutaneously applied magnesium protects reliably against quinolinateinduced N-methyl-D-aspartate (NMDA)mediated neurodegeneration and convulsions in rats: are there therapeutic implications? Neuroscience Letters, 117: 207211.

36. Kroll MH \& Elin RJ (1985). Relationship between magnesium and protein concentration in serum. Clinical Chemistry, 31: 244-246.

37. Inglefield J R, Perry J M \& Schwartz RC (1995). Postischemic inhibition of GABA reuptake by tiagabine slows neuronal death in the gerbil hippocampus. Hippocampus, 5: 460-468. 